\title{
Formalization of Behavior Change Theories to Accomplish a Health Behavior
}

\author{
Adnan Manzoor \\ Department of Information Technology \\ Quaid e Awam UEST \\ Nawabshah, Pakistan \\ Imtiaz Ali Halepoto \\ Department of Computer Systems Engineering \\ Quaid e Awam UEST \\ Nawabshah, Pakistan
}

\author{
Sohail Khokhar \\ Department of Electrical Engineering \\ Quaid e Awam UEST \\ Nawabshah, Pakistan \\ Nazar Hussain Phulpoto \\ Department of Information Technology \\ Quaid e Awam UEST \\ Nawabshah, Pakistan
}

\author{
Engr. Muhammad Sulleman Memon \\ Department of Computer Systems Engineering \\ Quaid e Awam UEST \\ Nawabshah, Pakistan
}

\begin{abstract}
The objective of this paper is to study theories behind behavior change and adaptation of behavior. Humans often live according to habitual behavior. Changing an existing behavior or adopting a new (healthier) behavior is not an easy task. There are a number of things which are important when considering adapting physical activity behavior. A behavior is affected by various cognitive processes, for example involving beliefs, intentions, goals, impediments. A conceptual and computational model is discussed based on state of the art theories about behavior change. The model combines different theories: the social cognitive theory, and the theory of selfregulation. In addition, health behavior interventions are discussed that may be used in a coaching system. The paper consists of two parts: the first part describes a computational model of behavior change and the second part discusses the formalization of evidence-based techniques for behavior change and questions to measure the various states of mind in order to provide tailored and personalized support.
\end{abstract}

Keywords-Behavior monitoring; healthy lifestyle; behavior change; physical activity; computational model

\section{INTRODUCTION}

In this paper we explore and study theories and models about behavior change, in which the particular focus is on adopting a healthy behavior. In this work we study what state of the art theories about behavior change propose and how a theory about health behavior change can be formalized in a way that it can be used with a mobile system to motivate and encourage young individuals to adopt a more physically active lifestyle. Mobile and sensor technology provide a promising way to support health behavior change interventions. Depending on what aspect of a healthy lifestyle is intended to be addressed, knowledge from different domains can be used. For instance, if the goal is to achieve a good mood or lowering daily life stress [1], [2], then theories related to emotion regulation could be used [3]. In the first half of this paper various theories related to behavior change are discussed and one of them is used to formalize in terms of a computational model. This computational model is implemented in the virtual coaching system whose purpose is to help young adults to physically be more active. The computational model is adopted from [4]. The second part discusses the identification of various behavior change techniques and how they can be used in a mobile system; this is based on [5]. In this part we explore theories and evidence based research to understand how different theories can play a role in the design and development of an intelligent coaching system that can help motivate people to achieve an active lifestyle. One of the first steps is to identify behavioral determinants of physical activity behavior. In this respect different health behavior models have been suggested in the literature, over the years different theories proposed different kinds of focal determinants for health behavior. Some of those theories and their focal determinants are discussed below. The computational model used by the coaching system to predict health behavior determinants. Each determinant (in the computational model) is linked to a behavior change technique and a number of motivational messages. These messages help user to increase their motivation level towards physical activity health behavior.

\section{THEORIES ON BEHAVIOR CHANGE}

In this section, we will review the most important (psychological) theories on behavior change. Based on this discussion, a computational model of behavior change will be presented in the subsequent section.

\section{A. The Transtheoretical Model}

The transtheoretical model proposes one theory of behavior change [6]. It consists of four major components: stages of 
change, processes of change, decisional balance, and selfefficacy. The model proposes that in order to change unhealthy behavior or adopt a healthy lifestyle, people go through six stages of change. These stages of change describe that a change of behavior occurs over a time period through different stages in different time slots. The first is precontemplation in which there is no awareness of the advantages and disadvantages of a behavior change and no change occurs in next six months. The Contemplation stage describes when people are better aware of the pros and cons of a behavior and in the next six months the change is likely. In the Preparation stage individuals are to change; this can take place in the next month. The Action stage is when people take the actual action to change the behavior. The Maintenance phase is when an individual avoids a situation where a relapse can happen; usually it lasts for a longer period of time which may be from six months to five years. In this stage usually individuals feel less temptation towards the unhealthy behavior. The last is the Termination stage determines the time point where a person do not feel any temptation to go back to the old habit.

\section{B. Health Belief Model}

Another model which is often referred to in health behavior literature and used in various empirical studies is the Health Belief model [7]. The Health belief model mainly consists of four constructs. Perceived susceptibility determines a person's subjective perspective on the risks of getting an illness, perceived severity is the belief which determines an individual's opinions about the seriousness of an illness. The last two are perceived benefits and perceived barriers; these are the beliefs concerning the potential benefits of adapting a healthy behavior and the likely hurdles one would face. If a person would give more weightage to potential benefits than the barriers, then he/she most likely adapt the behavior. Later the model was extended by including another construct: selfefficacy [8]. Self-efficacy is the extent to which a person believes that he/she is able to change his/her behavior; it is further discussed in the section about the Social Cognitive Theory below.

\section{Theory of Planned Behavior}

The Theory of planned behavior [9] is also one of the widely used models in health behavior, it is the extension of another theory by the same author, the theory of reasoned actions [10]. The model suggests that a health behavior is determined by attitudes and social influences through behavior intentions. Therefore, if an individual's attitude towards a health behavior is positive and a perceived social pressure to perform that health behavior is also present, then the individual's behavioral intention is higher to execute certain health behavior.

\section{Ecological Models of Behavior Change}

The proponents of ecological models propose that a population-wise change can only be achieved by taking into account various environmental factors; for example, a person's physical and social environment also play an important role in achieving behavior change. Ecological models [11] of health behavior suggest that there are more factors that could contribute to a health behavior than psychological and social factors. These may include a person's physical environment, but also other ecological factors are taken into consideration, for example, the physical infrastructure, the community of a person, the policies, etc.

\section{E. The Social Cognitive Theory}

In the area of active physical behavior, one of the most often used theories is the Social cognitive theory [12], [13]. The most important concept in social cognitive theory is selfefficacy. As mentioned above, self-efficacy is a person's confidence in his/her capabilities to perform a certain action successfully. A high self-efficacy is associated with strong determination in the wake of difficulties and not giving up. A low self-efficacy is associated with difficulty in performing/committing to a challenging task and to give up in the wake of difficulties. Self-efficacy can be strengthened by social support and satisfaction about a difficult task done in the past. Friends can also help a person to remind him/her about the person's success on a difficult task in the past. Furthermore, self-efficacy affects the behavior through multiple paths, it can affect it directly or it can affect it indirectly through intentions or outcome expectations. Self-efficacy plays an essential role in a number of behaviors. Different kinds of interventions have been proposed based on the targeted behavior, for example, for smoking cessation [5]. Further important determinants are satisfaction intentions, impediments, long term goals, social norms. Reciprocal determinism also is an important concept in the Social cognitive theory; it proposes that a person's behavior, his/her personal characteristics and his/her environment have reciprocal interactions to determine the subsequent behavior of the person. Outcome expectation is another important concept in the theory. It determines what people expect after performing an action, outcome expectation is further based on physical outcome expectations, social outcome expectations and personal outcome expectations. Physical outcome expectations determine the changes that are felt in the body, for example, after exercising one might have a good feeling. Social outcome expectations determine people's behavior towards the action which is carried out and personal outcome expectations represent the extent to which one expects to be better or worse off.

Impediment determines the obstacle one encounters during the course of an action or before performing an action. For example an individual might avoid going to sports school by bike if the weather is not conducive or if it is raining. Another common impediment is lack of time. Social norms affect the behavior through the intentions; social norm are people's reaction towards an action. Goals are also important ingredient of the Social cognitive theory; goals can be divided into distal/long term and proximal/short term (i.e. intentions).

\section{COMPUTATIONAL MODEL}

Given the fact that the Social cognitive theory is one of the most often used theories in the area of active physical behavior and that we also intend to apply it in practice, choosing this theory as the basis of creating a computational model is a natural choice. This section describes a formalization of this model. The conceptualization of the model is depicted in Fig. 1. 
Often in the literature, the emphasis is given to some determinants of the Social cognitive theory, but in the model that we present, all the ingredients are used. The model describes the dynamic relations among the determinants, which helps to understand how they work together to influence physical activity behavior. Below we discuss some of the concepts (with their formalization) in the model, they are adopted from [4], (for the remaining formalization please see preceding paper). Simulation result in Fig. 2 is adopted from [4], it suggest that when a person with inactive behavior encounters impediments it can cause an improvement in his/her behavior if he/she is able to surpass the potential impediments, for the rest of other results please see [4].

\section{A. Self-efficacy}

In the context of physical activity, the definition of selfefficacy is a person's judgment about his/her capability to successfully indulge in an active lifestyle. Self-efficacy can be strengthened by social comparison, social support, accomplishing a task successfully, and psychological responses (for example a person does not feel any anxiety or fear before giving a presentation). One of the sources of self-efficacy is satisfaction about a behavior or an accomplishment. A higher satisfaction leads to an increased self-efficacy and "a lower satisfaction level results in a decreased self-efficacy". It can be computed in the following way.

If $\operatorname{SE}(t) \geq \operatorname{Sat}(t): \operatorname{SE}(t+\Delta t)=\operatorname{SE}(t)+\beta_{\mathrm{Sat}, \mathrm{SE}} \cdot(\operatorname{Sat}(t)$

$-\mathrm{SE}(t)) \cdot \mathrm{SE}(t) \cdot \Delta t$

If $\operatorname{SE}(t)<\operatorname{Sat}(t): \operatorname{SE}(t+\Delta t)=\operatorname{SE}(t)+\beta_{\mathrm{Sat}, \mathrm{SE}} \cdot(\operatorname{Sat}(t)-\mathrm{SE}(t)) \cdot(1-$ $\operatorname{SE}(t)) \cdot \Delta t$

\section{B. Outcome Expectations}

Outcome expectations are described in terms of three further outcomes i.e. physical outcome expectations, social outcome expectations, and personal outcome expectations. OE is computed with the following formulas:

$$
\begin{aligned}
& \mathrm{OE} *(t)=\left(\omega_{\mathrm{SOE}} \cdot \operatorname{SOE}(t)+\omega_{\mathrm{POE}} \cdot \operatorname{POE}(t)+\omega_{\mathrm{PhOE}} \cdot \operatorname{PhOE}(t)\right) / \\
& \left(\omega_{\mathrm{SOE}}+\omega_{\mathrm{POE}}+\omega_{\mathrm{PhOE}}\right)
\end{aligned}
$$

$$
\begin{aligned}
& \text { If } \mathrm{OE}^{*}(t) \geq \mathrm{SE}(t): \mathrm{OE}(t+\Delta t)=\mathrm{OE}^{*}(t)+\beta_{\mathrm{SE}, \mathrm{OE}} \cdot\left(\mathrm{SE}(t)-\mathrm{OE}^{*}(t)\right) \\
& \cdot \mathrm{OE}^{*}(t) \cdot \Delta t \\
& \text { If } \mathrm{OE}^{*}(t)<\mathrm{SE}(t): \mathrm{OE}(t+\Delta t)=\mathrm{OE}^{*}(t)+\beta_{\mathrm{SE}, \mathrm{OE}} \cdot(\mathrm{SE}(t)- \\
& \left.\mathrm{OE}^{*}(t)\right) \cdot\left(1-\mathrm{OE}^{*}(t)\right) \cdot \Delta t
\end{aligned}
$$

\section{Impediments}

Confidence in one's capability can help overcome an impediment. Other factors also play a role to avoid temptations and overcome impediments, for example self-regulation. But, if a person's self-efficacy level is higher it helps him/her to be stronger in the face of difficulties. It is computed by the difference between self-efficacy and the impediments.

$$
\begin{aligned}
& \operatorname{If} \operatorname{SE}(t) \geq \operatorname{Imp}(t): \operatorname{Imp}(t+\Delta t)=\operatorname{Imp}(t)-\beta_{\mathrm{SE}, \operatorname{Imp}} \cdot(\operatorname{SE}(t)-\operatorname{Imp}(t)) \cdot \\
& \operatorname{Imp}(t) \cdot \Delta t \\
& \text { If } \operatorname{SE}(t)<\operatorname{Imp}(t): \operatorname{Imp}(t+\Delta t)=\operatorname{Imp}(t)-\beta_{\mathrm{SE}, \operatorname{Imp}} \cdot(\operatorname{SE}(t)-\operatorname{Imp}(t)) \cdot(1- \\
& \operatorname{Imp}(t)) \cdot \Delta t
\end{aligned}
$$

\section{Intentions}

Intentions are short term goals. Outcomes expectations influence in the process of goal formation, as people aim for those action for which they expect positive consequences. Selfefficacy and outcome expectations together determine intentions. Furthermore, intentions are also affected by the impediments and the facilitators.

$$
\begin{aligned}
& \text { Change_Int }(t)=\beta_{\mathrm{SE}, \operatorname{Int}} \cdot(\operatorname{SE}(t)-\operatorname{Int}(t))+\beta_{\mathrm{SOE}, \operatorname{Int}} \cdot(\operatorname{SOE}(t)- \\
& \operatorname{Int}(t))+\beta_{\mathrm{Fac}, \operatorname{Int}} \cdot \operatorname{Fac}(t)-\beta_{\mathrm{Imp}, \operatorname{Int}} \cdot \operatorname{Imp}(t) \\
& \text { If Change_Int }(t) \geq 0: \operatorname{Int}(t+\Delta t)=\operatorname{Int}(t)+\text { Change_Int }(t) \cdot(1-\operatorname{Int}(t)) \\
& \Delta t \\
& \text { If Change_Int }(t)<0: \operatorname{Int}(t+\Delta t)=\operatorname{Int}(t)+\text { Change_Int }(t) \cdot \operatorname{Int}(t) \cdot \Delta t \\
& \text { E. Satisfaction }
\end{aligned}
$$

\section{E. Satisfaction}

As seen in Fig. 1, the satisfaction has incoming edges from three states i.e. behavior, intention, and facilitators/impediments. It is computed by combining these states in the following formula.

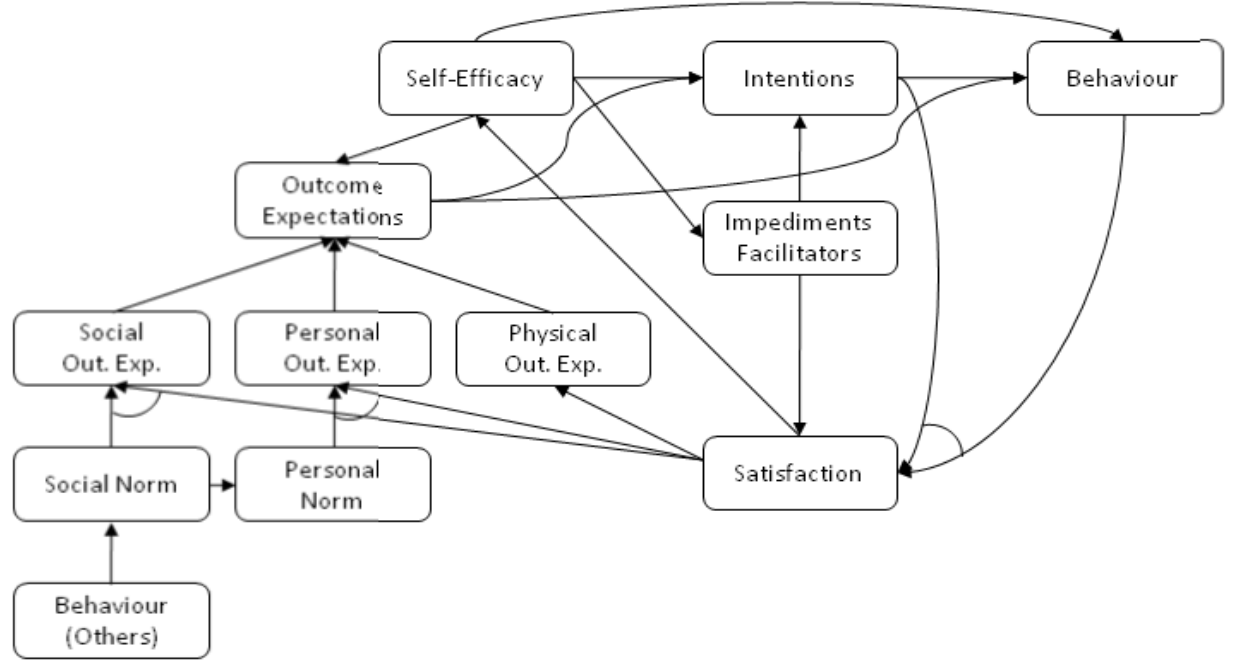

Fig. 1. A computational model for behavior change based on the social cognitive theory; the model is adopted from [4]. 
Change_Sat $(t)=\beta_{\text {Int\&Beh,Sat }} \cdot(\operatorname{Beh}(t)-\operatorname{Int}(t))+\beta_{\operatorname{Imp}, \text { Sat }} \cdot \operatorname{Imp}(t)-$

$\beta_{\mathrm{Fac}, \mathrm{Sat}} \cdot \operatorname{Fac}(t)$

If Change_Sat $(t) \geq 0: \operatorname{Sat}(t+\Delta t)=\operatorname{Sat}(t)+$ Change_Sat $(t) \cdot(1-$

$\operatorname{Sat}(t)) \cdot \Delta t$

If Change_Sat $(t)<0: \operatorname{Sat}(t+\Delta t)=\operatorname{Sat}(t)+$ Change_Sat $(t) \cdot \operatorname{Sat}(t) \cdot \Delta t$

\section{F. Behavior}

Behavior is influenced by self-efficacy, outcome expectations, and intentions. It is implemented in similar way: there are incoming edges from these states to behavior. In the current context a behavior describes a person's activity level, if value of 0 shows that person is not active and a value of 1 describes that the individual is very active.

Change_Beh $(t)=\beta_{\mathrm{SE}, \mathrm{Beh}} \cdot(\mathrm{SE}(t)-\mathrm{Beh}(t))+\beta_{\mathrm{OE}, \mathrm{Beh}} \cdot(\mathrm{OE}(t)-$ $\operatorname{Beh}(t))+\beta_{\text {Int,Beh }} \cdot(\operatorname{Int}(t)-\operatorname{Beh}(t))+\beta_{\mathrm{Fac}, \operatorname{Beh}} \cdot \operatorname{Fac}(t)-\beta_{\mathrm{Imp}, \mathrm{Beh}} \cdot \operatorname{Imp}(t)$

If Change_Beh $(t) \geq 0: \operatorname{Beh}(t+\Delta t)=\operatorname{Beh}(t)+$ Change_Beh $(t) \cdot(1-$ $\operatorname{Beh}(t)) \cdot \Delta t$

If Change_Beh $(t)<0: \operatorname{Beh}(t+\Delta t)=\operatorname{Beh}(t)+$ Change_Beh $(t) \cdot$ $\operatorname{Beh}(t) \cdot \Delta t$

\section{PROPOSING AND IMPLEMENTING BeHAVIOR CHANGE TECHNIQUES}

The second part of this paper is concerned with the formalization of behavior change techniques (BCTs). This section is partially based on the research conducted in [5]. We first discuss the relation between behavior change and modern (mobile/sensor) technology, then we describe the concept of tailoring, and finally we identify BCTs and describe how they can be translated into actual tailored messages that can be used within a mobile system for stimulating physical activity. The BCTs described in [5] are adopted from the widely used taxonomy proposed by Michie et al. They suggested a standardized collection of BCTs which can be linked to various determinants in a theoretical framework [14].

\section{A. Behavior Change Techniques and Modern Technology}

A smartphone is an inherently a personalized device and therefore it seems to be a well suited medium to implement
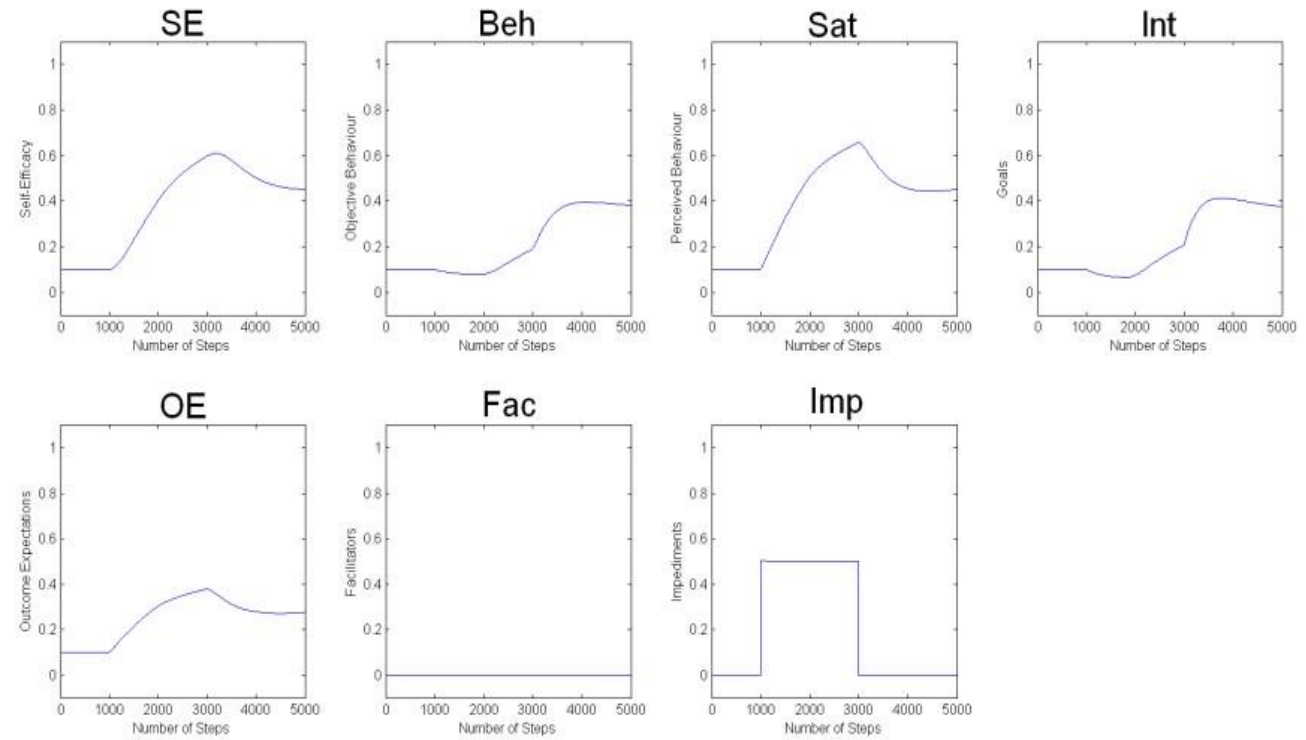

Fig. 2. An example simulation scenario of the model, as presented in (Mollee \& van der Wal, 2013). 
Personal informatics is another synonym term for quantified-self, Li et al. conducted a survey, and based on it they propose their five stages model to self-discovery [19]. The first stage corresponds to preparation; this stage takes place before starting a system. It consists of mainly two things: what kind of information people are motivated to record and what kind of software or wearable/tracker people would like to use or a combination of both. In this stage people face difficulties because every kind of tool has its own format and using multiple tools or switching between tools can lead to loss of information that was recorded previously. Another problem is that initially people are motivated enough to use a variety of tools, but after some time their motivation becomes less. Collection is the second stage in which people actually start recording data about different aspects of their personal life. In this stage people encounter problems that sometimes there is a lack of motivation or lack of time. The next stage is Integration; the challenge in this stage is to combine and integrate the data when it comes from multiple sources. It could lead to problems to move to next stage of Reflection which helps the person to explore and think about different aspects of the information. And Action is the last stage when people need to take certain action based on their new self. While technologies such as Personal Informatics and Wearables are promising for behavior change, their potential for behavior change tools can be leveraged by using evidencebased behavior change techniques and established behavior change models such as discussed in Section 2 of this paper.

\section{B. Tailored Messages}

There is difference between computer generated and computer tailored feedback [20], [21]. Computer generated feedback is merely a static delivery of contents without any personalization features attached to the feedback. In contrast, in computer tailored feedback an individual's psychological, social, and physical states are measured and then based on that the tailored feedback is generated by applying some algorithm(s). Moreover, there is also a difference between dynamically tailored and static tailored feedback. In the dynamic variant, timely feedback is generated based on ongoing assessment, while static feedback is based on onetime assessment [20]. It has been shown that dynamically tailored feedback is significantly better, It also has been found that tailored messages have stronger effect than non-tailored messages [21]. Tailored messages require strategies/suggestions that are targeted to an individual based on his/her unique mental, physiological and environmental attributes rather than for an entire group, which are often referred as targeted generic messages [21]. In practice, software tailored messages have also shown more promising results then untailored messages [21] .

\section{Behavior Change Techniques in a mobile support system}

To implement an automated support system for behavior change, we should identify evidence-based techniques which can be linked in an algorithmic way to the computational analysis of the determinants of behavior change. In this section, we identify appropriate BCTs (in the physical activity domain) based on the literature (Michie et al., 2013) and link them to behavior determinants that were identified in the previous model (see Section 2). Second, it should be decided how to implement various BCTs. For example, one of the ways is to implement them in terms of feedback messages. The messages need to be tailored to each individual. Various measures can be used to personalize the messages, i.e. an individual's activity data, location data, social network and behavior determinants which can be determined by various questions.

In Table I, an overview is provided on how determinants used in the computational model described in Section 3 are related to BCTs from the taxonomy of Michie and how they can be applied in a mobile support system. The table also shows from which behavior change theory the determinants stem (see Section 2).

\section{CONCLUSION}

In this paper various theories related to behavior change were discussed. The Social Cognitive Theory is a widely used theory in the domain of physical activity behavior. A model based on this theory which was earlier formalized [4] is adopted in this paper. The objective of the computational model is to provide a computational means for reasoning about behavior change in a coaching system. We have discussed that modern technology such as wearables do help to achieve a behavior change to some extent but they do not yet fulfill the role of a personalized coaching system. Based on a model, a coaching system can predict behavior and generate context specific tailored messages for the users of the system. These messages are based on evidence-based strategies [5] to improve physical activity behavior, which are linked to particular BCTs and determinants in the model. Currently state of the art techniques (which are based on mobile apps) to improve health behavior do not support evidence-based behavior change techniques [15].

If the tailored interventions are combined with network interventions [22] they have a great potential for strengthening health behavior change. Social network interventions can play an important role to achieve a behavior change by utilizing the structure of the network and measuring various characteristics (mental and physical states) of individuals in the network. In addition to personalized feedback, this provides the possibility to create another type of support based on different social phenomena such as social support, social comparison, social contagion, etc. A number of strategies [22], [23] exist to find people in a social network who can work as change agents. For instance, it is possible to identify people in a social network based on the similar characteristics who can provide social support to each other. Social interventions are especially relevant as one of the important behavior change technique related to self-efficacy is social modelling or social comparison through which self-efficacy can be improved/increased [24]. A number of social interventions are proposed above, but further research can be done on implementing them in support systems. 
TABLE I. List of Determinants, Related Behavior Change TeChNiques AND THE Possible IMPLEMENTATION IN AN Automated System. Note That THE TABLE IS ADOPTED FROM ANOUK MIDDELWEERD ET AL. 2017

\begin{tabular}{|l|l|l|}
\hline Determinant & Behavior Change Technique & Implementation \\
\hline $\begin{array}{l}\text { Outcome } \\
\text { Expectations }\end{array}$ & $\begin{array}{l}\text { Provide general information on consequences of } \\
\text { behavior in general }\end{array}$ & Message in general and tailored to aspects of the questionnaire \\
\hline Self-efficacy & Action planning/ time management & Message \\
\hline & Social comparison & Graph tailored to preference social comparison (up-/ down wards \\
\hline & Persuasion & Persuasive massages on how to overcome barriers \\
\hline & Prompt self-monitoring & Message \& graph \\
\hline & Plan social support & Message \\
\hline Intention & Imaginary reward & Message \\
\hline & Progress towards goal & Message \\
\hline & Motivational messages & Message \\
\hline & Modeling & Message \& graph \\
\hline & Prompt instruction & message \\
\hline Impediments & Prompt goal setting & Message \& suggestion \\
\hline $\begin{array}{l}\text { Social Norm } \\
\text { (Descriptive and } \\
\text { Inductive) }\end{array}$ & Social comparisons & message \\
\hline & Information about other's approval & Graph tailored to preference social comparisons (up-/ down \\
& wards \\
\hline Self-regulation & self-monitoring & message \\
\hline & Goalsetting & Graph \& message \\
\hline & Progress towards goal & Message \\
\hline & Self-evaluation & Graph \& message \\
\hline Satisfaction & Imaginary reward & message \\
\hline Long-term goals & Self-evaluation & message \\
\hline & behavior in general & message \\
\hline
\end{tabular}

\section{REFERENCES}

[1] A. H. Abro, M. C. A. Klein, A. R. Manzoor, S. A. Tabatabaei, and J. Treur, "Modeling the effect of regulation of negative emotions on mood," Biol. Inspired Cogn. Archit., vol. 13, pp. 35-47, Jul. 2015.

[2] L. Medeiros and T. Bosse, "Empirical Analysis of Social Support Provided via Social Media," in Social Informatics, 2016, pp. 439-453.

[3] J. J. Gross, "The emerging field of emotion regulation: An integrative review,” Rev. Gen. Psychol., vol. 2, no. 3, pp. 271-299, 1998.

[4] J. S. Mollee and C. N. van der Wal, "A computational agent model of influences on physical activity based on the social cognitive theory," in International Conference on Principles and Practice of Multi-Agent Systems, 2013, pp. 478-485.

[5] Anouk Middelweerd, Saskia J te Velde, Julia S Mollee, Michel CA Klein, and Johannes Brug, "Description of the development and content of Active2Gether: an app-based intervention combining evidence-based behavior change techniques with a model-based reasoning system to promote physical activity among young adults," J. Med. Internet Res. Rev., 2017.

[6] J. O. Prochaska and W. F. Velicer, "The Transtheoretical Model of Health Behavior Change," Am. J. Health Promot., vol. 12, no. 1, pp. 3848, Sep. 1997.

[7] M. H. Becker, "The health belief model and sick role behavior," Health Educ. Monogr., vol. 2, no. 4, pp. 409-419, 1974.

[8] I. M. Rosenstock, V. J. Strecher, and M. H. Becker, "Social learning theory and the health belief model," Health Educ. Q., vol. 15, no. 2, pp. 175-183, 1988 .

[9] I. Ajzen, "From intentions to actions: A theory of planned behavior," in Action control, Springer, 1985, pp. 11-39.

[10] M. Fishbein and I. Ajzen, "Belief, attitude, intention, and behavior: An introduction to theory and research," 1977.

[11] J. F. Sallis, R. B. Cervero, W. Ascher, K. A. Henderson, M. K. Kraft, and J. Kerr, "An ecological approach to creating active living communities," Annu Rev Public Health, vol. 27, pp. 297-322, 2006.

[12] A. Bandura, "Health promotion from the perspective of social cognitive theory," Psychol. Health, vol. 13, no. 4, pp. 623-649, 1998.
[13] A. Bandura, "Health promotion by social cognitive means," Health Educ. Behav., vol. 31, no. 2, pp. 143-164, 2004.

[14] S. Michie et al., "The behavior change technique taxonomy (v1) of 93 hierarchically clustered techniques: building an international consensus for the reporting of behavior change interventions," Ann. Behav. Med., vol. 46, no. 1, pp. 81-95, 2013.

[15] A. Middelweerd, J. S. Mollee, C. N. van der Wal, J. Brug, and S. J. te Velde, "Apps to promote physical activity among adults: a review and content analysis," Int. J. Behav. Nutr. Phys. Act., vol. 11, no. 1, p. 97, 2014.

[16] E. J. Lyons, Z. H. Lewis, B. G. Mayrsohn, and J. L. Rowland, "Behavior change techniques implemented in electronic lifestyle activity monitors: a systematic content analysis," J. Med. Internet Res., vol. 16, no. 8, p. e192, 2014.

[17] E. K. Choe, N. B. Lee, B. Lee, W. Pratt, and J. A. Kientz, "Understanding quantified-selfers' practices in collecting and exploring personal data," in Proceedings of the 32nd annual ACM conference on Human factors in computing systems, 2014, pp. 1143-1152.

[18] M. Swan, "Health 2050: The realization of personalized medicine through crowdsourcing, the quantified self, and the participatory biocitizen,” J. Pers. Med., vol. 2, no. 3, pp. 93-118, 2012.

[19] I. Li, A. Dey, and J. Forlizzi, "A stage-based model of personal informatics systems," in Proceedings of the SIGCHI Conference on Human Factors in Computing Systems, 2010, pp. 557-566.

[20] P. Krebs, J. O. Prochaska, and J. S. Rossi, "A meta-analysis of computertailored interventions for health behavior change," Prev. Med., vol. 51, no. 3, pp. 214-221, 2010

[21] M. W. Kreuter, V. J. Strecher, and B. Glassman, "One size does not fit all: the case for tailoring print materials," Ann. Behav. Med., vol. 21, no. 4, pp. 276-283, 1999.

[22] T. W. Valente, "Network interventions," Science, vol. 337, no. 6090, pp. 49-53, 2012.

[23] S. P. Borgatti, "Identifying sets of key players in a social network," Comput. Math. Organ. Theory, vol. 12, no. 1, pp. 21-34, 2006.

[24] N. Michinov, "Social comparison, perceived control, and occupational burnout," Appl. Psychol., vol. 54, no. 1, pp. 99-118, 2005. 